\title{
Strategies for Teaching Social Studies to English-Language Learners at the Elementary Level
}

\author{
EVELYN MARINO WEISMAN \\ LAURIE E. HANSEN
}

\begin{abstract}
Learning social studies curriculum can present challenges for English-language learners (ELLs). The language used to present concepts is often decontextualized and abstract, making it difficult for these students to understand the content and have successful learning experiences. In this article, the authors describe strategies elementary teachers can use to make social studies content more comprehensible to ELLs and engage them to become active participants in their learning. They discuss three strategies in-depth and explain particular teaching techniques, such as the use of graphic organizers. Teaching vignettes illustrate ways these strategies can be implemented in the classroom to help ELLs be successful in acquiring social studies knowledge and inquiry skills while developing critical English language arts proficiencies.
\end{abstract}

Keywords: elementary, English language learners (ELLs), social studies curriculum

EVELYN MARINO WEISMAN is an associate professor in the department of elementary and bilingual education at California State University, Fullerton. LAURIE E. HANSEN is a lecturer in the department of elementary and bilingual education at California State University, Fullerton.
A cross the United States, teachers are encountering students in their classrooms who are in the process of learning English as a second language. In the past two decades, this student population, known as English-language learners (ELLs), has more than doubled, reaching nearly ten million people in 2004 (U.S. Department of Education 2004). In California, 25 percent of public school enrollment, or one and a half million students, are ELLs, and the vast majority are in elementary schools (California State Department of Education 2005). Although California and states such as Texas, Florida, and New York have experienced the largest enrollments of ELLs, all states have been affected by their presence in public schools (Nieto 2004). Being a successful teacher increasingly means knowing how to address the special needs of these students. Because of the linguistic demands of social studies content, ELLs may have particular difficulty understanding this subject area. Despite these difficulties, the social studies present an important avenue for ELLs' success because this subject provides students the opportunity to share their experiences related to culture, language, and knowledge. In this article, we illustrate how elementary teachers can make social studies content more comprehensible to ELLs while engaging students to become active participants in their learning.

\section{Challenges for Teachers of ELLs}

Many teachers have a wide variety of cultures and languages represented in their classrooms. This presents a challenge in communicating with students and understanding their cultures. In addition, a range of abilities and different backgrounds often exist among ELLs. Whereas some ELLs are born in the United States and have attended American schools for a number of years, others may be recent arrivals who have received little or no schooling in their native country. Other children may have attended school in their native country, providing them with an academic foundation that will facilitate their success in U.S. schools.

Fewer than one-fourth of all ELLs in U.S. public schools receive instruction in their native language, and the majority of teachers report feeling unprepared to teach them (Nieto 2004). At the same time, federal and state governments are calling for all students, including ELLs, to meet high standards and demonstrate proficiency on state tests. This means 
that teachers are faced with the challenge of finding ways to help ELLs learn content that is presented to them entirely in English, a language they are still struggling to master.

Social studies may be the most difficult subject for ELLs. Some educators believe that when transitioning students from native language instruction to learning subjects in English, social studies should be taught in English only when the students are at an advanced level of proficiency in English. They believe this because, unlike subjects such as math or science, understanding social studies concepts depends to a large extent on language skills. This is particularly true as students move from the primary to upper elementary grades. For example, language must be used as a tool to understand abstract concepts such as justice, liberty, responsibility, and democracy. Students must be able to learn much of social studies content primarily through listening and reading, and often the information is decontextualized with few, if any, concrete referents (Chamot and O'Malley 1994); there are no meaningful visual cues or demonstrations to support understanding. Students must step outside their familiar world and use information that is removed from their everyday experiences. Students also must express understanding of the concepts presented by participating in discussions and debates and giving oral reports. Thus, successful learning depends heavily on knowledge of vocabulary and linguistic structures and background knowledge of the topic. The linguistic demands of social studies require teachers to find ways to provide contextual support that allow ELLs to understand concepts and develop the language skills they need to succeed.

\section{How to Help ELLs Succeed}

For students to understand subject matter while they are acquiring Englishlanguage skills requires adaptations to instruction. Sheltered instruction, also referred to as specially designed academic instruction in English (Echevarria, Vogt, and Short 2000), is a teaching approach that uses techniques to make content accessible to ELLs or that makes language and concepts visible (De Jong and Harper 2005). The purpose of sheltered instruction is twofold: (1) to teach content and (2) to teach academic language. These are important components of effective instruction for ELLs because in addition to developing understanding of social studies concepts, students must be able to use language to learn and express what they know. The sheltered approach includes many strategies, such as the teacher speaking clearly, emphasizing and repeating key points, defining vocabulary in context, and coupling talk with the use of gestures, drawings, graphs, and charts. This does not mean that teachers should water down curriculum for ELLs. The aim is to present the regular grade-level curriculum to ELLs, but teachers must provide appropriate scaffolding, or contextual support, to ensure that the content is comprehensible to ELLs (Chamot and O'Malley 1994). In addition, effective sheltered instruction provides ELLs with frequent opportunities for social interaction to reinforce learning and promote the production of language, including content-specific terms (Peregoy and Boyle 2005). In the following sections, we identify typical difficulties that ELLs encounter, describe strategies for addressing their needs, and provide specific examples of how the strategies can be implemented during social studies lessons.

\section{Background Knowledge}

Students who are learning English may lack background knowledge in social studies topics. Some children come from poor backgrounds and may not have had formal schooling in their home countries. Consequently, they may not be familiar with concepts about geography, history, or government even as they relate to their native countries. In contrast, students who possess adequate background knowledge will understand concepts better. Students who have studied social science in their native language will be able to transition more easily into learning social studies in English.
Another problem is that the background knowledge students possess, referred to by some scholars as "funds of knowledge" (Moll et al. 1992), may not be valued by the school. For example, ELLs may have extensive knowledge of their culture and communities, but it is often ignored as a potential resource because many teachers are unfamiliar with the culture of their students and how to bring it into the curriculum (Sleeter and Grant 1999). Teachers who learn as much as possible about their students will be better able to tap into this background knowledge to facilitate understanding. The following example illustrates how a teacher can build on ELLs' prior knowledge and connect new information with their own experiences to make it more meaningful.

Vignette 1: Anna is a fifth-grade teacher with many ELLs from a variety of countries in her classroom. Anna begins a social studies unit on immigration and migration in the United States by reading Grandfather's Journey (Say 1993) to the class. This story describes a Japanese man's journey to America. After reading the story, Anna opens a satchel full of items representative of those that her own grandfather brought when he came to the United States from Denmark. Anna explains the reasons her grandfather left his native country and shows the students his travel route on a map. As Anna shows the class the items, she talks about each one, recalling events from her grandfather's journey to America through Ellis Island in the early 1900s. Some of the items include a comb, a shaving kit with a bar of soap and a thick-bristled brush, some Danish money to exchange for American dollars, a toothbrush, and a photograph of loved ones back home. Anna then asks the children to think about why people leave their homeland and what items they would bring with them. Some of the children have journeyed from other countries to America. Others have never taken such a journey but can imagine what would be needed in these circumstances. For homework, she asks them 
to interview a family member about their journeys or those of past generations, draw it on a map, and bring some items that relate to that journey. The next day, the students work with partners to share their maps and talk about what they brought and why the items are meaningful to family members. The class then discusses factors that contribute to people moving from one place to another.

In this vignette, the concepts about and causes for immigration and migration are introduced through a children's book and expanded on by the teacher's personal family history. The teacher also uses realia, or real objects, to add interest and help convey meaning. The use of real objects, charts, pictures, or photographs is an essential feature of effective instruction for ELLs because they provide a necessary support to construct meaning (Dunlap and Weisman 2006; Echevarria and Graves 1998; Law and Eckes 2000). In addition, asking the students to bring objects, photographs, or drawings related to their own family stories of immigration or migration provides an explicit link with their background knowledge, which will help them understand the upcoming lessons about immigration and settlement patterns of American people. Connecting with students' personal lives and existing knowledge also acknowledges the value of these resources as building blocks for their learning. Obtaining insight into students' backgrounds can be valuable to understanding cultural and social factors that influence learning (Ovando, Combs, and Collier 2006).

The background experiences of many students, including ELLs, offer many opportunities for making links to new learning about topics such as immigration and migration. However, many social studies concepts are not easily bridged and pose a challenge for making those critical connections that facilitate learning. In such cases, the teacher may consider using role play as a means of constructing the schemata or background knowledge necessary for understanding new information (Ovando, Combs, and Collier 2006).
For example, students can play the roles of colonists, the king of England, and the king's representative to dramatize the concept of taxation without representation and how it led to increasing conflict between the American colonies and Great Britain. Acting out situations can facilitate comprehension of difficult concepts by making them more concrete. It also stimulates interest, provides and see and understand relationships between ideas.

Along with strategies that provide comprehensible input, ELLs must have opportunities to produce academic language. Researchers suggest that interaction with others and language output is just as important as input to language development (Swain 1985). As students communicate with others, both

\section{Connecting the curriculum with students' personal lives and knowledge of their own cultures acknowledges the value of these resources as building blocks for their learning.}

excellent opportunities for discussing different perspectives, and engages students in language practice.

\section{Making Content Comprehensible: Graphic Organizers and Student Interaction}

An important consideration is that students may quickly acquire conversational skills, but it may take much longer for them to develop literacy skills and academic language (Cummins 1994). Academic language is the abstract language used for instruction that typically has no context clues to support meaning. A particular challenge for ELLs is reading and writing because academic language in social studies is complex and abstract. Textbooks are written at grade-level readability, and ELLs may not be able to read at grade level in English. Furthermore, students may find the order of words in English sentences confusing. Social studies textbooks often use passive voice and intricate sentences that can make it difficult for ELLs to understand passages. Graphic organizers are an effective teaching tool that can support understanding of difficult concepts and text. Graphic organizers such as Venn diagrams, series of events chains, compare and contrast matrixes, and T-charts help students construct meaning from text orally and in writing, about what they are studying, they will improve their language skills and conceptual understanding. When students read for information, create timelines, or write and present reports, they are practicing literacy skills that are essential for academic success. The following vignette offers ideas for integrating language activities into content instruction to develop subject-matter knowledge and language skills.

Vignette 2: José is a fourth-grade teacher who has a mix of ELLs and native English speakers in his classroom. He is teaching a unit on Native Americans. The children have been learning about different Native American tribes that lived in geographic regions throughout the United States. In addition to the textbook, José has used pictures, Native American literature, historical documents, and oral histories to convey concepts. In the middle of the unit, José asks the children to work in groups to review the information they have learned and compare regional Native American tribes. In each group of four to five students, there are ELLs and native English speakers. Each group creates a chart comparing characteristics of Native American life, such as housing, climate, tools, food sources, and traditions of Native 
Americans from regions such as the Southwest, Northwest, Great Plains, and Northeast (see table 1). After the charts are completed, they are posted around the classroom and serve as a springboard for discussion about similarities and differences among the tribes and the range of perspectives offered by different sources of information. Throughout the discussion, José paraphrases and expands on the students' ideas and writes them on the board for the class to read aloud with him. Last, José asks the students to write a summary of what they have learned about the Native American tribes.

In this example, the students use a graphic organizer sometimes referred to as a process grid (Brechtal 2001) to categorize the information they have been learning about Native American tribes. By visually displaying and organizing the information, students can more easily see relationships among concepts. In this vignette, students also had the opportunity to talk with each other about what concepts they were learning. As the students worked together to complete the grid, they discussed and shared information, thereby integrating the learning of content with practice in using academic language. Ideally, groups should consist of a variety of learning and language levels so students can support and learn from one another. Working in a small, supportive group also generally fosters a relaxed, lowanxiety atmosphere for students. Establishing a learning environment that is low in anxiety is particularly important to second-language acquisition (Krashen 1994). Along these lines, it is important to keep in mind the different Englishlanguage proficiency levels of students and adjust expectations and questions accordingly. For example, beginners may be expected to respond only using short phrases, whereas the expectation for more advanced students is that they use complete sentences and elaborate on their ideas.

Vignette 2 also illustrates how a teacher can model and reinforce language skills while teaching social studies. By paraphrasing, elaborating on key concepts, writing these on the board, and engaging students in reading and writing, the teacher explicitly modeled oral and written forms of academic language and provided practice with sentence structures and skills that enable students to communicate complex ideas. Moreover, providing multiple sources of information can familiarize students with issues and points of view not addressed in the traditional textbook and infuse an important multicultural perspective into the curriculum. As students discuss and compare information gleaned from a variety of sources, they develop an understanding of how cultural biases and values can influence knowledge construction (Banks 1999).

\section{Vocabulary Development}

Without adequate word knowledge, students will be unable to make sense of much of the content in social studies lessons. Vocabulary development is essential for all students' success and presents a special challenge for ELLs. Many words have dual meanings: their common use and a specific definition for social studies. For example, the term inflation means to fill, as with air in a balloon, but in economics, it means a rise in the general price level. Many other terms, such as taxation and liberty, represent complex ideas that require concrete examples to develop understanding. Although textbooks typically highlight keywords, there are often many other terms within a lesson that are unfamiliar to ELLs. Students will benefit from activities that promote active involvement and provide varied opportunities for them to practice and apply knowledge of words. In the following vignette, a teacher develops vocabulary knowledge through frequent exposure to words and an engaging activity to promote language practice.

Vignette 3: Alicia teaches sixth grade at an intermediate school in an urban school district. At least one-third of her students are ELLs, and she knows they need additional support. Therefore, when teaching a social studies unit, she divides vocabulary into manageable chunks. When she teaches a unit on Ancient Egypt, there are many vocabulary words such as hieroglyphics, irrigation, cartouche, pyramid, pharaoh, sarcophagus, mummification, and afterlife. Rather than teaching all the vocabulary at once at the beginning of a unit, she introduces the vocabulary for each lesson as she teaches it. Alicia makes extensive use of pictures and realia to teach five or six words per lesson. She writes the

TABLE 1. Comparison of Native American Tribes

\begin{tabular}{|c|c|c|c|}
\hline Cultural region & Example tribes & Housing & Food sources \\
\hline Northwest & Chinook, Makah & Pit house & Salmon, elk, deer \\
\hline Southwest & $\begin{array}{l}\text { Hopi, Navajo, } \\
\text { Pueblo }\end{array}$ & Hogan & $\begin{array}{l}\text { Rabbit, squash, corn, } \\
\text { beans, sheep }\end{array}$ \\
\hline Great Plains & $\begin{array}{l}\text { Mandan, Kiowa, } \\
\text { Blackfoot, Dakota }\end{array}$ & $\begin{array}{l}\text { Lodge, } \\
\text { tepee }\end{array}$ & $\begin{array}{l}\text { Buffalo, game, } \\
\text { corn, beans, squash, } \\
\text { melon }\end{array}$ \\
\hline Northeast & $\begin{array}{l}\text { Iroquois League } \\
\text { (Mohawk, Onondaga, } \\
\text { Oneida), Cherokee }\end{array}$ & $\begin{array}{l}\text { Longhouse, } \\
\text { pit house }\end{array}$ & $\begin{array}{l}\text { Game, fish, corn, } \\
\text { squash, beans }\end{array}$ \\
\hline
\end{tabular}


words on a word wall, explains their meanings, provides examples, and draws pictures to help convey meaning. She asks students to work with the words by using them in sentences and sharing these with partners. The words remain on the word wall throughout the unit, and Alicia refers to them often as they come up in the context of lessons. Students collect vocabulary words as they progress through the unit, writing a definition for each in their own words and drawing a corresponding picture. Alicia also asks students to record words they do not understand as they encounter them in the text. These words are then discussed and explained and added to student dictionaries. For review, Alicia asks the children to work in groups of five or six to create definitions for a class Jeopardy game. The students are given a list of vocabulary words and work together to write each definition on a separate overhead transparency sheet. When playing the game with the whole class, each team sends a representative to the front of the room to display one definition (e.g., "the body of a person or animal that has been preserved"). The other teams try to figure out what vocabulary word each definition represents (in this case, "What is a mummy?").

In this example, understanding of difficult vocabulary is developed through (1) explicit instruction using visual aids to help convey meaning and (2) frequent repetition throughout the unit. Effective instruction for ELLs is characterized by the extensive use of realia, pictures, and drawings that can support student understanding of concepts. In this scenario, the teacher also uses a word wall, which can be an effective way to teach and reinforce content vocabulary because the words are posted for the teacher and students to refer to frequently (Echevarria, Vogt, and Short 2000). In addition, reducing the number of words presented at one time makes the learning more manageable, and involving the students in creating their own dictionaries provides them with a valuable personal resource. The teacher also realizes that words other than those highlighted in the textbook may be unfamiliar to ELLs and provides for opportunities to teach these as well. Last, because vocabulary is best learned in the context of interesting activities, engaging students in a game can be an excellent way to reinforce vocabulary knowledge. In this example, students had to talk with one another to develop definitions and match definitions with key terms. We stress that, in addition to learning word definitions, students need a variety of opportunities to practice and apply knowledge of new words. In this way, students engage in language practice that can move them to a higher level of language ability.

\section{Conclusion}

The ELLs in the vignettes are actively engaged in learning in ways that promote understanding of content and acquisition of language skills that are crucial for academic success. It takes time to build background knowledge, implement graphic organizers, and provide for student interaction opportunities, but these are essential elements in social studies instruction that aims to develop gradelevel skills in ELLs. If a major purpose of social studies curriculum is to prepare informed citizens who can participate fully in their society, instruction must help all students become knowledgeable about key issues and develop the ability to become thoughtful participants in the classroom. By providing ELLs with appropriate scaffolding, teachers can facilitate their learning a rigorous curriculum, develop their English-language skills, and promote their active participation in the classroom.

\section{REFERENCES}

Banks, J. 1999. An introduction to multicultural education. Boston: Allyn and Bacon.

Brechtal, M. 2001. Bringing it all together: Language and literacy in the multilingual classroom. Carlsbad, CA: Dominie.

California State Department of Education. 2005. Language census 2004-2005. http://www.cde.ca.gov/index.asp (accessed August 6, 2006).

Chamot, A. U., and J. M. O'Malley. 1994. The CALLA handbook: Implementing the cognitive academic language learning approach. New York: Longman.

Cummins, J. 1994. Primary language instruction and the education of language minority students. In Schooling and language minority students: A theoretical framework, ed. C. E. Leyba, 3-46. Sacramento: California State Department of Education.

De Jong, E., and C. Harper. 2005. Preparing mainstream teachers for English language learners. Teacher Education Quarterly 32 (2): 101-24.

Dunlap, C. Z., and E. M. Weisman. 2006. Helping English language learners succeed. Huntington Beach, CA: Shell Educational.

Echevarria, J., and A. Graves. 1998. Sheltered content instruction: Teaching English language learners with diverse abilities. Boston: Allyn and Bacon.

Echevarria, J., M. Vogt, and D. Short. 2000. Making content comprehensible for English learners: The SIOP model. 2nd ed. Boston: Allyn and Bacon.

Krashen, S. D. 1994. Bilingual education and second language acquisition theory. In Schooling and language minority students: A theoretical framework, ed. C. E. Leyba, 47-75. Sacramento: California State Department of Education.

Law, B., and M. Eckes. 2000. The morethan-just-surviving handbook: ESL for every classroom teacher. Winnipeg, MB, Canada: Portage and Main.

Moll, L., C. Amanti, D. Neff, and N. Gonzalez. 1992. Funds of knowledge for teaching: Using a qualitative approach to connect homes and classrooms. Theory into Practice 31 (2): 132-41.

Nieto, S. 2004. Affirming diversity: The sociopolitical context of multicultural education. 4th ed. Boston: Allyn and Bacon.

Ovando, C. J., M. C. Combs, and C. P. Collier. 2006. Bilingual and ESL classrooms: Teaching in multicultural contexts. 4th ed. Boston: McGraw-Hill.

Peregoy, S., and O. Boyle. 2005. Reading, writing and learning in ESL: A resource book for K-12 teachers. 3rd ed. Boston: Pearson Education.

Say, A. 1993. Grandfather's journey. New York: Walter Lorraine.

Sleeter, C., and C. Grant. 1999. Making choices for multicultural education: Five approaches to race, class, and gender. Upper Saddle River, NJ: Merrill.

Swain, M. 1985. Communicative competence: Some roles of comprehensible input and comprehensible output in its development. In Input in second language acquisition, ed. S. Gass and C. Madden, 235-53. New York: Newbury.

U.S. Department of Education. 2004. Language minority school-age children. Washington, DC: National Center for Education Statistics. http://www.nces .ed.gov (accessed August 6, 2006). 
Copyright of Social Studies is the property of Heldref Publications and its content may not be copied or emailed to multiple sites or posted to a listserv without the copyright holder's express written permission. However, users may print, download, or email articles for individual use. 